\title{
The Role of Tumor Markers for Evaluation the Course of Chemotherapy
}

\author{
Suela Bushi $^{1^{*}}$, Artan Trebicka ${ }^{2}$ \\ ${ }^{I}$ Clinical Biochemical Laboratory, Regional Hospital of Vlore, Albania \\ ${ }^{2}$ Faculty of Natural Sciences, University of Tirana, Albania
}

*Corresponding Author: Suela Bushi, Clinical Biochemical Laboratory, Regional Hospital of Vlore, Albania

\begin{abstract}
Gynecological tumors, including endometrial, cervical and ovarian cancer, have increased in incidence over time. The widespread introduction of screening programs and advances in diagnostic imaging methods has lead to a progressive increase in gynecological cancer detection. Accurate diagnosis and proper monitoring of disease remain the primary target for a successful treatment. In the last years, knowledge about cancer biomarkers has considerably increased providing great opportunities for improving cancer detection and treatment. In addition, in the last few years there has been an important development of imaging techniques. Nowadays, a multimodal approach including the evaluation of serum tumor biomarkers combined with imaging techniques, seems to be the best strategy for assessing tumor presence, spread, recurrence, and/or the response to treatment in female cancer patients In this review we provide an overview of the application of biomarkers combined with novel imaging methods and highlight their roles in female cancer diagnosis and follow-up.
\end{abstract}

Keywords: gynecologic malignancy, tumor markers, chemotherapy

\section{INTRODUCTION}

Of the millions of new cases of cancer worldwide and deaths associated with cancer, a large number of them were breast and gynecological tumors (Molina $\mathrm{R}$ et al., 2005). Some tumor markers are fundamental to the workflow in diagnosis, control of therapy and the monitoring of advanced gynecological diseases (Sturgeon CM et al 2010). The biomarker should be absent in healthy people as well as in good conditions and it is released exclusively from specific tumor cells (Duffy MJ et al 2013). Tumor markers are soluble glycoproteins that are found in the blood, urine, or tissues of patients with certain types of cancer. They are typically produced by tumor cells, but in some cases they may be produced by the body in response to malignancy or to certain benign conditions. Tumor markers are not elevated in all cancer patients, particularly patients with early-stage cancer. The various tumor markers differ in their usefulness for screening, diagnosis, prognosis, assessing therapeutic response, and detecting recurrence. Normalization of tumor marker values may indicate cure despite radiographic evidence of persistent disease. In this situation, residual tumor is frequently nonviable. Sometimes, tumor marker values may rise after effective treatment (due to cell lysis), but the increase may not portend treatment failure. A consistent increase in a tumor marker value, combined with lack of clinical improvement, may indicate treatment failure. Residual elevation after definitive treatment usually indicates persistent disease. Many new tumor markers have been discovered since the development of monoclonal antibodies, and most tumor markers are now detected with them. No marker is completely specific. Therefore, diagnostic immunohistochemistry must be used in conjunction with morphologic and clinical findings. [2]Among asymptomatic persons, the biomarker should allow for the examination of early cancer or premalignant disease and in symptomatic patients the biomarker should help in the differential diagnosis of benign and malignant disease. After diagnosis, an ideal biomarker should also be used to estimate the prognosis and predict the most appropriate treatment. For patients receiving systemic therapy, the level of expression should correlate with therapeutic response and tumor burden (Duffy MJ et al 2015). A biomarker should contribute to improving beneficial clinical outcomes such as increased overall survival (OS), progression-free disease survival (PFS) or 
reduced cost of care (Di Gioia et al 2011, Lufter $\mathrm{D}$ et al 2000). CA125 is currently the most commonly used serological biomarker for the management of patients with some of the fallopian tubes or the vesicles. In recent years, the prognostic value of changes in serum levels of CA15-3 for breast cancer has gained a lot of attention (Ali HQ et al 2013). For multiple cancers, markers of serum tumors play important roles in early diagnosis, prognosis, and response for specific therapies, early detection of recurrence after curative surgery, and monitoring of therapy for patients with advanced disease (Tarhan MO et al., 2013). Tumor-like markers widely used for breast cancer are CA15-3 and CEA (Kim HS et al 2009). While the CA15-3 level is rarely elevated for patients with early stage or localized cancer, most metastatic breast cancer patients have demonstrated elevated serum levels of CA15- 3 (Nisman B et al., 2013). In the absence of measurable lesion (s), however, an increasing CA15-3 level can be used to indicate the failure of treatment (Zhang SJ et al 2013). More attention should be given to the interpretation of increased CA15-3 levels during the first 4-6 weeks of new therapy due to early premature growth (Thriveni $\mathrm{K}$ et al 2013). The temporary increase of CA15-3 that is affected by chemotherapy and followed by the decrease of CA15-3 (CA15-3 increases and decreases) may result in inappropriate early discontinuation or chemotherapy change.The vast majority of ovarian tumors are of epithelial origin and the 125 carbohydrate antigen (CA 125) is the most important marker of tumor. Increased levels depend on the histological type and stage of the disease (Sölétormos G et al 2016). Though it is sensitive in the early stages, CA 125 has high sensitivity and specificity in early dictation of the disease, especially in women and premenopause period (Castrillon DH et al 2002). Furthermore, some factors may cause high levels of CA 125, such as ethnicity, pregnancy, age, premenopausal postmenopausal period and menstrual cycle (Pauler DK et al 2001). In breast cancer, a combination of carcinoembryonic antigen (CEA) and CA 15-3 has prognostic potential in a preoperative environment (Huh JW et al 2010). While CEA and CA 15-3 are recommended for monitoring the therapy and early detection of disease recurrences they are also recommended for early diagnosis or screening due to their high sensitivity. In cervical cancer, the guidelines of the National Academy of Clinical Biochemistry (NACB) discuss (among the markers of other tumors such as the CEA and CA 125 squamous cell carcinoma antigen (SSCA) for predicting prognosis and preoperative prediction of metastases ( Colombo $\mathrm{N}$ et al 2016) CEA has prognostic significance in colorectal cancer (Thirunavukarasu $\mathrm{P}$ et al 2011) but in cases where the origin of an uterine tumor is unclear, panel tumor markers are recommended including CEA (Zur B et al 2012, Haas M et al., 2013). The aim of the study is to monitor the alteration of tumour markers after chemotherapy.

\section{Material AND Methods}

This is a prospective study performed during the period 2014-2016 with 107 patients diagnosed with breast, uterine and ovarian cancer in the hospital of Vlora district who also were treated with chemotherapy. For all patients, laboratory tests: biochemical, hematologic, tumor markers: CEA (mg / l) CA15.3 (U / ml) CA 125 (U / ml) were performed after the first and second cycle of chemotherapy. The reported data are expressed as mean \pm standard deviation (SD). Wilcoxon test was used to compare the hematobiochemic and tumor markers between the $1^{\text {st }}$ and $2^{\text {nd }}$ cycle of chemotherapy. The receiver operating curve (ROC) curves for determining cut-off values and predictive parameters of tumor markers for $\mathrm{Ca}$. A p-value $\leq 0.05$ was considered statistically significant.

\section{RESUltS AND DISCUSSION}

The mean age of patients was57.1 $( \pm 8.13)$ years and ranging from 38 to 70 years of age. Table 1 shows the study subjects' demographic characteristics and clinical history. By comparing the median values of hematobiochemic and tumor parameters after the $1^{\text {st }}$ and $2^{\text {nd }}$ cycle of chemotherapy, the statistically significant difference was found only for aspartate aminotransferase (AST) which showed decrease after the second cycle. Concerning the types of $\mathrm{Ca}$, significant decrease of CA 15.3, CA 125 and CEA was observed in all three types of $\mathrm{Ca}$ following the second cycle of chemotherapy $(\mathrm{p}<0.01)$. The values of the three tumor markers are significantly higher in metastatic patients, as compared to metastasisfree patients $(\mathrm{p}<0.01)$ (table 2).No statistically significant difference was found between the ROC curves of the three tumor markers for the determination of $\mathrm{Ca}$ (figure 1).In predicting malignancy in ovarian tumor patients, besides history taking and physical examination, the use of tumor markers as a part of evaluation is also important. 
The Role of Tumor Markers for Evaluation the Course of Chemotherapy

Table1: Demographic characteristics and clinical history of study participants

\begin{tabular}{|l|l|l|}
\hline Variables & $\mathrm{N}$ & $\%$ \\
\hline Age of $1^{\text {st }}$ menarche M (SD) & $13.5(2.4)$ & \\
\hline Age of ${ }^{\text {st }}$ sexual intercourse & & 17.8 \\
\hline$\leq 18$ & 19 & 82.2 \\
\hline$>18$ & 88 & \\
\hline Pregnant & & 15.0 \\
\hline No & 16 & 85.0 \\
\hline Yes & 91 & \\
\hline Parity & & 15.0 \\
\hline Nullipara & 16 & 29.9 \\
\hline Primipara & 32 & 55.1 \\
\hline Multipara & 59 & \\
\hline Sectio Caesarea & & 57.0 \\
\hline No & 61 & 43.0 \\
\hline Yes & 46 & \\
\hline Abortions & & 76.6 \\
\hline No & 82 & 23.4 \\
\hline Yes & 25 & \\
\hline Historyfor STI & & 6.5 \\
\hline No & 7 & 93.5 \\
\hline Yes & 100 & \\
\hline Family history for Ca & & 96.3 \\
\hline No & 103 & 3.7 \\
\hline Yes & 4 & \\
\hline
\end{tabular}

Table2: Mean values of tumor markers according to presence of metastasis

\begin{tabular}{|l|c|c|c|}
\hline Metastasis & CEA $(\mu \mathrm{g} / \mathrm{l})$ & CA $15.3(\mathrm{U} / \mathrm{ml})$ & CA 125 $(\mathrm{U} / \mathrm{ml})$ \\
\hline Yes & $55.8 \pm 25.9$ & $122.3 \pm 89.2$ & $288.4 \pm 206.7$ \\
\hline No & $13.2 \pm 218$ & $78.6 \pm 89.8$ & $201.4 \pm 197.1$ \\
\hline P & $<0.01$ & $<0.01$ & $<0.01$ \\
\hline
\end{tabular}

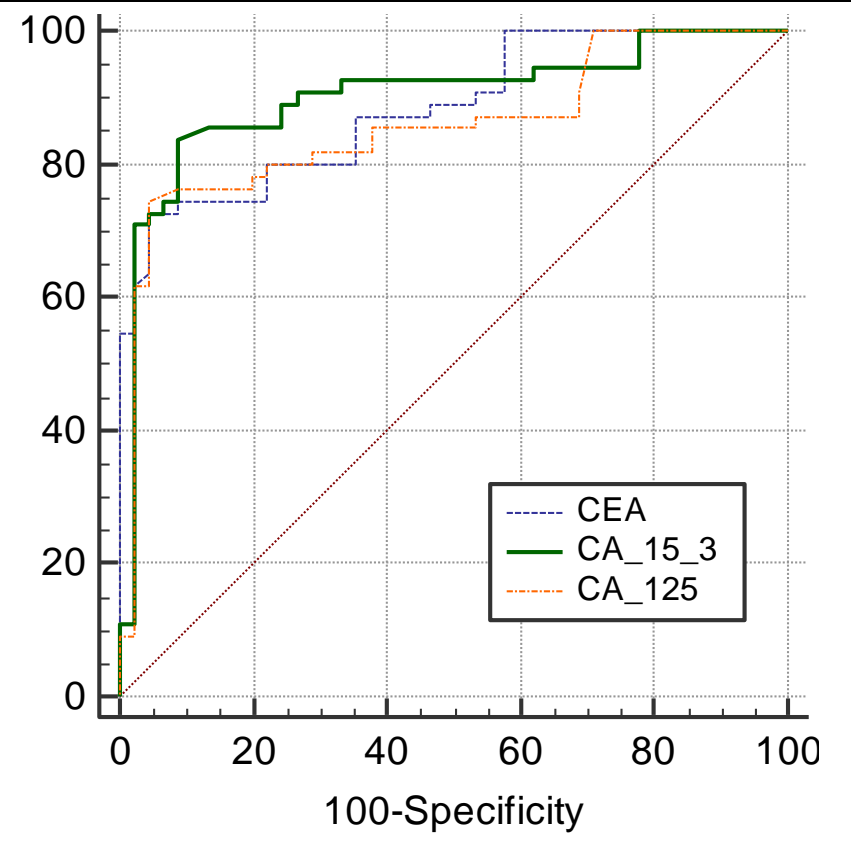

Figure1: Comparison of ROC curves of tumor markers for the evaluation of $\mathrm{Ca}$

Patients receiving first line chemotherapy for ovarian cancer are usually offered a minimum of 5 courses of chemotherapy. Unless there is evidence of clinical progression the first three courses will almost certainly be administered. If there is then evidence of inadequate response or progression when the patient attends for her fourth or subsequent course, there could be a change of therapy. A serial rise of tumor markers of $25 \%$ over three samples has been shown to indicate progression. Many doctors would consider a lesser rise or slight fall 
indicates poor response. It is essential that any decision is based on a baseline result and at least two further marker results with the second or subsequent marker results confirming the trend. To summarise: Obvious clinical improvement: continue planned therapy. Obvious clinical progression: change therapy. If patients not in above groups: Marker response (at least downward trend): continue planned therapy. Marker progression (>25\% rise) chnage therapy.Our findings correspond to current guidelines such as NACB that recommend CA 15-3 in breast cancer - although not for diagnosis but for advanced disease monitoring and postoperative surveillance. Although the CEA application is still being discussed, various studies have shown its importance in, for example, anticipating and early detection of disease progression and metastasis (Stieber $\mathrm{P}$ et al 2015). While in the breast cancer analysis the our results show the high clinical performance of CA 15-3.

In ovarian cancer, the best diagnostic performance was achieved for CA 125 . These results are in line with current recommendations, suggesting that CA 125 is of major importance in therapeutic monitoring, differential diagnosis for legal measures, recurrence and prognosis (Sölétormos $\mathrm{G}$, et al 2016)Serum Cancer Biomarker Cancer Antigen 125 (CA125) is proposed as an adjunct to noninvasive procedures in patients with advanced disease (Shao Y et al 2015; Wu SG et al 2014; Wang $G$ et al 2014). However, challenges remain on how to determine values in CA125 concentrations that allow an optimal interpretation that is vital for early diagnosis of tumor growth.

\section{Conclusions}

The values of hematobiokimic parameters and tumor markers are important in identifying the course of therapy as well as predicting malignant conditions.Accurate determination of serum tumor marker levels is crucial, as their impact on diagnosis, prognosis, and therapy monitoring has been shown for many types of tumors.

\section{REFERENCES}

[1] Molina R, Barak V, Van Dalen A, et al. Tumor markers in breast cancer-European Group on Tumor Markers recommendations. Tumour Biol 2005; 26: 281-293.

[2] Sturgeon CM, Duffy MJ, Hofmann BR, et al. National Academy of Clinical Biochemistry Laboratory Medicine Practice Guidelines for use of tumor markers in liver, bladder, cervical, and gastric cancers. Clin Chem 2010; 56: e148.

[3] Duffy MJ. Tumor markers in clinical practice: a review focusing on common solid cancers. Med PrincPract2013; 22:4-11.

[4] Duffy MJ, Sturgeon CM, Soletormos G, et al. Validation of new cancer biomarkers: a position statement from the European group on tumor markers. Clin Chem 2015;61:809-20

[5] Di Gioia D, Heinemann V, Nagel D, Untch M, Kahlert S, Bauerfeind I, et al. Kinetics of CEA and CA15-3 correlate with treatment response in patients undergoing chemotherapy for metastatic breast cancer (MBC). Tumour Biol 2011; 32:777- 85 .

[6] Lufter D, Richter A, Gunther S, Flath B, Akrivakis C, Geppert R, et al. A comparison of bone-related biomarkers and CA27.29 to assess response to treatment of osseous metastatic breast cancer. Anticancer Res 2000;20(6D):5099-105.

[7] Ali HQ, Mahdi NK, Al-Jowher MH. The value of CA15-3 in diagnosis, prognosis and treatment response in women with breast cancer. J Pak Med Assoc 2013; 63: 1138-41.

[8] Tarhan MO, Gonel A, Kucukzeybek Y, Erten C, Cuhadar S, Yigit SC, et al. Prognostic significance of circulating tumor cells and serum CA15-3 levels in metastatic breast cancer, single center experience, preliminary results. Asian Pac J Cancer Prev 2013;14:1725-9

[9] Kim HS, Park YH, Park MJ, Chang MH, Jun $\mathrm{HJ}$, Kim $\mathrm{KH}$, et al. Clinical significance of a serum CA15-3 surge and the usefulness of CA15-3 kinetics in monitoring chemotherapy response in patients with metastatic breast cancer. Breast Cancer Res Treat 2009; 118:8997.

[10] Nisman B, Maimon O, Allweis T, Kadouri L, Maly B, Hamburger T, et al. The prognostic significance of LIAISON(R) CA15-3 assay in primary breast cancer. Anticancer Res 2013; 33:293-9.

[11] Zhang SJ, Hu Y, Qian HL, Jiao SC, Liu ZF, Tao HT, et al. Expression and significance of ER, PR, VEGF, CA15-3, CA125 and CEA in judging the prognosis of breast cancer. Asian Pac J Cancer Prev2013; 14:3937-40.

[12] Thriveni K, Deshmane V, Ramaswamy G, Krishnamoorthy L. Diagnostic significance of CA15-3 with combination of HER- 2/neu values at 85 th percentiles in breast cancer. Indian J Clin Biochem 2013;28: 136-40.

[13] Sölétormos G, Duffy MJ, Hassan SOA, et al. Clinical use of cancer biomarkers in epithelial ovarian cancer: updated guidelines from the European Group on Tumor Markers (EGTM). Int J Gynecol Cancer 2016; 26: 43-51.

[14] Castrillon DH, Lee KR and Nucci MR. Distinction between endometrial and endocervical adenocarcinoma: an immune 
histochemical study. Int J GynecolPathol2002; 21: 4-10.

[15] Pauler DK, Menon U, McIntosh M, et al. Factors influencing serum CA125II levels in healthy postmenopausal women. Cancer Epidemiol Biomarkers Prev2001; 10: 489-493.

[16] Huh JW, Oh BR, Kim HR, et al. Preoperative carcinoembryonic antigen level as an independent prognostic factor in potentially curative colon cancer. J Surg Oncol 2010; 101: 396-400.

[17] Colombo N, Creutzberg C, Amant F, et al. ESMO-ESGOESTRO consensus conference on endometrial cancer: diagnosis, treatment and follow-up. Int J Gynecol Cancer 2016; 26: 2-30.

[18] Thirunavukarasu P, Sukumar S, Sathaiah M, et al. C-stage in colon cancer: implications of carcinoembryonic antigen biomarker in staging, prognosis, and management. J Natl Cancer Inst 2011; 103: 689-697.

[19] Zur B, Holdenrieder S, Albers E, et al. Method comparison for CA 15-3, CA 19-9, and CA 125 determination using the new LOCI technique of Dimension Vista 1500 and Immulite 2000 XPI. J Immunoassay Immunochem2012; 33: 435445.

[20] Haas M, Heinemann V, Kullmann F, et al. Prognostic value of CA 19-9, CEA, CRP, LDH and bilirubin levels in locally advanced and metastatic pancreatic cancer: results from a multicenter, pooled analysis of patients receiving palliative chemotherapy. $J$ Cancer Res Clin Oncol 2013; 139: 681-689

[21] Stieber P, Nagel D, Blankenburg I, et al. Diagnostic efficacy of CA 15-3 and CEA in the early detection of metastatic breast cancer: a retrospective analysis of kinetics on 743 breast cancer patients. Clin Chim Acta 2015; 448: 228-231.

[22] Shao Y, Sun X, He Y, Liu C, Liu H. Elevated levels of serum tumor markers CEA and CA153 are prognostic parameters for different molecular subtypes of breast cancer. PLoS One 2015; 10:e0133830.

[23] Wu SG, He ZY, Zhou J, Sun JY, Li FY, Lin Q, et al. Serum levels of CEA and CA15- 3 in different molecular subtypes and prognostic value in Chinese breast cancer. Breast 2014; 23:88-93.

[24] Wang G, Qin Y, Zhang J, Zhao J, Liang Y, Zhang Z, et al. Nipple discharge of CA15-3, CA125, CEA and TSGF as a new biomarker panel for breast cancer. Int J Mol Sci 2014; 15:9546-65.

Citation: Suela Bushi, Artan Trebicka. The Role of Tumor Markers for Evaluation the Course of Chemotherapy. ARC Journal of Cancer Science. 2021; 7(1):01-05. DOI: dx.doi.org/10.20431/2455-6009. 0701001.

Copyright: (C) 2021 Authors. This is an open-access article distributed under the terms of the Creative Commons Attribution License, which permits unrestricted use, distribution, and reproduction in any medium, provided the original author and source are credited. 